\title{
Effect of Temperature on Fracture Parameters of Aluminum Alloy Al 6061: A Numerical Study
}

\author{
Abhijeet Singh ${ }^{1 *}$, Hira Lal Yadav ${ }^{2}$, Shalendra Kumar ${ }^{1}$ \\ ${ }^{1}$ Department of Mechanical Engineering, NIT Jamshedpur, Jharkhand 831013, India \\ ${ }^{2}$ Physics Department, NIT Jamshedpur, Jharkhand 831013, India
}

Corresponding Author Email: abhijeetsingh315@gmail.com

https://doi.org/10.18280/acsm.430208

Received: 13 January 2019

Accepted: 2 April 2019

\author{
Keywords: \\ crack mouth opening displacement, crack \\ tip opening displacement, stress intensity \\ factor, ANSYS, side edge notch bend \\ specimen
}

\begin{abstract}
The fracture parameters of a material are affected by several operating parameters. The temperature of the specimen is one of the factors that significantly affects the fracture parameters. This paper presents the numerical investigation on fracture parameters at elevated temperatures and at different loads for a three-point bend test specimen having through thickness crack. The temperature of the specimen in the study varies from $25^{\circ} \mathrm{C}$ to $350^{\circ} \mathrm{C}$. The increase in temperature of the specimen changes the mechanical property of the material, which in turn changes the fracture parameter. The current study shows that the rise in temperature of the specimen at a constant load causes an increase in the values of crack mouth opening displacement and crack tip opening displacement, while the stress intensity factor is found to be independent of test temperature.
\end{abstract}

\section{INTRODUCTION}

The development of mankind and the culture has led to the increased use of metals in day to day life. This increase in applications of materials in engineering design has posed several challenges. The most important of all is the fracture of the structure. The past has witnessed several such failures of engineering structure that led to the loss of money and life as well. Since metal- working and engineering component design and fabrication is costly and laborious task, it requires enormous research to develop such material with the desired properties. One of the most important property studied is the fracture property of the metal. This study comes under a broad field of fracture mechanics, which deals with the parameters affecting the initiation and propagation of crack. The crack that originates in a structure is liable to propagate or not is determined using several fracture parameters that are studied extensively for the same. These fracture parameters include: stress intensity factor (SIF), crack mouth opening displacement (CMOD), crack tip opening displacement (CTOD), and J-integral. Amongst these parameters, CTOD serves as a versatile method to treat crack problems [1].

The concept of CTOD was introduced by Wells [2-3] for the first time for ductile materials failing under linear elastic fracture mechanics (LEFM) i.e. for the materials in which the plastic zone size is less than the crack size. According to Wells, the crack extension takes place when the material at the crack tip reaches a maximum permissible strain. This strain at the crack tip i.e. the CTOD is calculated using CMOD or the SIF, which are measurable quantities. The values of these parameters depend highly on the mechanical properties of the material, the shape and size of the crack [4], load applied, specimen thickness [5] and the thermal conditions.

The temperature at which the metal is being worked highly affects the mechanical properties of the metal which in turn affects the fracture properties. Several researches have been conducted to study the effect of temperature on the mechanical properties of the metal [6-8]. Both experimental and numerical modelling has been used to determine the mechanical properties of the material at elevated temperature. In the light of the temperature, manuals and codes have been developed stating about the mechanical properties at high temperature [910]. The fracture properties have been studied at elevated temperature for aluminum alloys. Hadianfard et al. [11] studied the fracture behaviour of alumina particulate 6061 aluminum composite at different temperatures in the range of $25{ }^{0} \mathrm{C}$ to $180{ }^{0} \mathrm{C}$. Derpeński et al. [12-13] presented the experimental fracture test results and numerical analysis results for notched aluminum alloy specimen under elevated temperature conditions stating a decrease in the mechanical properties at elevated temperature. Su and Young [14] studied the variation in the mechanical properties of Al $6061 \mathrm{~T} 6$ alloy at elevated temperature varying from $24{ }^{\circ} \mathrm{C}$ to $600{ }^{\circ} \mathrm{C}$.

A good agreement between the results obtained from the numerical analysis and experimental results has led to an increase in the application of numerical techniques for simulating the experiments and solving real time problems. This paper depicts the use of the numerical analysis tool ANSYS to study the fracture parameters for Al 6061 alloy under different working temperature and different loading conditions. The different fracture properties such as CMOD, CTOD, and SIF has been determined for a specimen having a through thickness crack and made according to the ASTM standards. The CMOD and CTOD are found to increase with an increase in temperature at a given load, however, the SIF values are almost constant with the increase in the temperature at a constant load.

\section{NUMERICAL ANALYSIS}

A simplified finite element analysis software (ANSYS) is used for the study of aluminum alloy at elevated temperature. The numerical analysis process involves two steps: modelling 
of the specimen and applying the boundary conditions. A three-point bend specimen is modelled for the study as it is considered as the best specimen for the study of fracture parameters. The size of the specimen is chosen according to the ASTM standards such that the state of plane strain prevails along the greater part of the crack tip. The shape and size of the specimen is shown in figure 1 . The size of the specimen is chosen as a/W $=0.5, \mathrm{~W} / \mathrm{B}=4$, and $\mathrm{W} / \mathrm{S}=4$ in order to maintain plane strain condition.

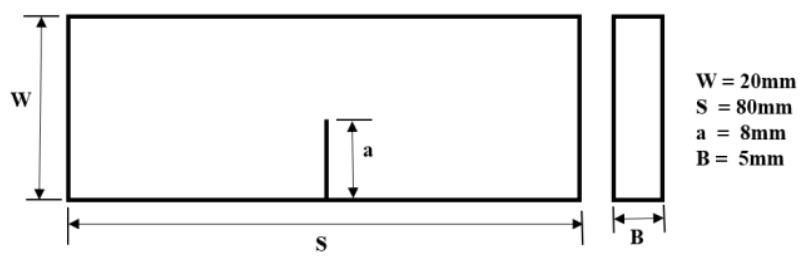

Figure 1. Typical dimension of the modelled test piece

The rise in working temperature of a material leads to the change in the mechanical properties. The present study deals with the determination of fracture properties at temperatures varying from $25{ }^{\circ} \mathrm{C}$ to $350{ }^{\circ} \mathrm{C}$. The mechanical properties of $\mathrm{Al} 6061$ at these elevated temperatures has been taken from the literature [14]. The properties such as the young's modulus, yield strength and ultimate tensile strength of Al 6061 at elevated temperature is being presented in Table 1.

Table 1. Mechanical properties of Al 6061 at elevated temperatures [14]

\begin{tabular}{ccccc}
\hline $\begin{array}{c}\text { Sl. } \\
\text { No. }\end{array}$ & $\begin{array}{c}\text { Temperature } \\
\left(\mathbf{(}^{\mathbf{0}} \mathbf{C}\right)\end{array}$ & $\begin{array}{c}\text { Young's } \\
\text { Modulus } \\
(\mathbf{G P a})\end{array}$ & $\begin{array}{c}\text { Ultimate } \\
\text { Tensile } \\
\text { Strength } \\
\text { (MPa) }\end{array}$ & $\begin{array}{c}\text { Yield } \\
\text { Strength } \\
\text { (MPa) }\end{array}$ \\
\hline 1. & 25 & 69.5 & 232.3 & 199.9 \\
2. & 100 & 63.388 & 225.331 & 195.902 \\
3. & 200 & 62.699 & 197.455 & 175.912 \\
4. & 250 & 58.565 & 190.486 & 175.912 \\
5. & 300 & 57.876 & 188.163 & 181.909 \\
6. & 350 & 54.431 & 169.579 & 163.918 \\
\hline
\end{tabular}

Different models have been prepared with different mechanical properties pertaining to the different working temperature. The schematic of the model is shown in figure 2 . These models are loaded accordingly with different loads varying from $100 \mathrm{~N}$ to $500 \mathrm{~N}$. The specimen is fine meshed in order to obtain accurate results (Figure 3).

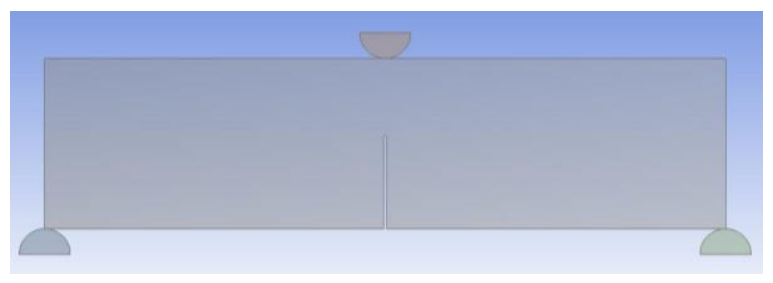

Figure 2. Model of specimen under three-point load

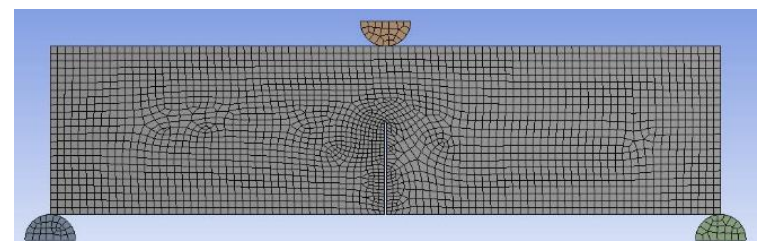

Figure 3. Meshed geometry

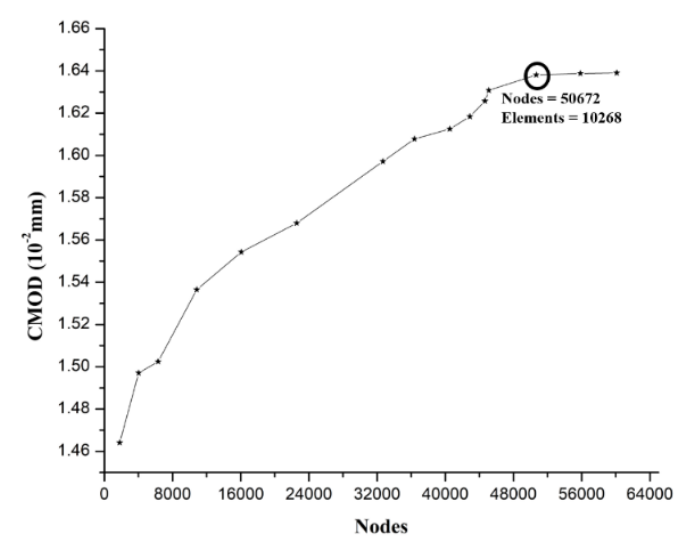

Figure 4. Convergence judgement of CMOD at $300 \mathrm{~N}$ and $25^{0} \mathrm{C}$

Table 2. Data acquired from the numerical analysis

\begin{tabular}{|c|c|c|c|c|c|c|c|c|c|c|c|c|}
\hline \multirow[b]{2}{*}{$\begin{array}{c}\text { Temperature } \\
{ }_{0}^{0} \mathrm{C}\end{array}$} & \multicolumn{3}{|c|}{ Load $=100 \mathrm{~N}$} & \multicolumn{3}{|c|}{ Load $=200 \mathrm{~N}$} & \multicolumn{3}{|c|}{ Load $=300 \mathrm{~N}$} & \multicolumn{3}{|c|}{ Load $=500 \mathrm{~N}$} \\
\hline & $\begin{array}{c}\text { CMOD } \\
(\mu \mathrm{m})\end{array}$ & $\begin{array}{c}\text { CTOD } \\
(\mu \mathrm{m})\end{array}$ & $\begin{array}{c}\text { SIF } \\
\left(\text { MPa.mm }^{0.5}\right)\end{array}$ & $\underset{(\mu \mathrm{m})}{\text { CMOD }}$ & $\begin{array}{c}\text { CTOD } \\
(\mu \mathrm{m})\end{array}$ & $\begin{array}{c}\text { SIF } \\
\left(\text { MPa.mm }^{0.5}\right)\end{array}$ & $\underset{(\mu \mathrm{m})}{\text { CMOD }}$ & $\begin{array}{c}\text { CTOD } \\
(\mu \mathrm{m})\end{array}$ & $\begin{array}{c}\text { SIF } \\
\left(\text { MPa.mm }^{0.5}\right)\end{array}$ & $\begin{array}{c}\text { CMOD } \\
(\mu \mathrm{m})\end{array}$ & $\begin{array}{c}\text { CTOD } \\
(\mu \mathrm{m})\end{array}$ & $\begin{array}{c}\text { SIF } \\
\left.\text { (MPa.mm }^{0.5}\right)\end{array}$ \\
\hline 25 & 5.456 & 0.53 & 2.846 & 10.919 & 2.10 & 5.7881 & 16.379 & 4.73 & 8.6821 & 27.299 & 13.13 & 14.47 \\
\hline 100 & 5.9423 & 0.85 & 2.8848 & 11.885 & 3.41 & 5.7697 & 17.827 & 7.68 & 8.6545 & 29.712 & 21.33 & 14.424 \\
\hline 200 & 6.0013 & 0.96 & 2.8797 & 12.003 & 3.83 & 5.7593 & 18.004 & 8.62 & 8.639 & 30.06 & 23.93 & 14.398 \\
\hline 250 & 6.383 & 1 & 2.8486 & 12.768 & 4.01 & 5.6971 & 19.151 & 9.03 & 8.5457 & 31.919 & 25.07 & 14.243 \\
\hline 300 & 6.4528 & 1.06 & 2.8433 & 12.906 & 4.24 & 5.6867 & 19.358 & 9.53 & 8.53 & 32.264 & 26.48 & 14.217 \\
\hline 350 & 6.8241 & 1.13 & 2.8172 & 13.648 & 4.53 & 5.6344 & 20.472 & 10.19 & 8.4516 & 34.12 & 28.31 & 14.086 \\
\hline
\end{tabular}

In order to check the reliability of the finite element model to calculate the CMOD values and to obtain an optimum value of nodes and elements, the convergence judgement of CMOD is done. The judgement is being done by increasing the mesh density and identifying the value of CMOD at that mesh density. Figure 4 shows the relationship between the number of nodes and the CMOD value. It can be seen that as the mesh density increases, the CMOD value also increases and after a certain point the CMOD value almost becomes asymptotic and becomes stable. This point represents the point after which the FEA model becomes precise and reliable and the CMOD values can be calculated accurately.

The numerical analysis of the specimen at different temperatures and different loads has been successfully completed and the results are tabulated and shown in Table 2. 


\section{RESULTS AND DISCUSSIONS}

The values of the different fracture parameters namely CMOD, CTOD and SIF at different temperatures and different loads have been generated and tabulated in table 2 . The data so generated is analyzed on the underlying principle of solid mechanics. The temperature indeed has an effect on the mechanical properties of the specimen. As the temperature increases, the mechanical properties such as Young's modulus, yield strength and ultimate tensile strength decreases considerably which in turn affects the fracture properties. The effect of temperature on the different fracture parameters are as below:

\subsection{Effect of temperature on crack mouth opening displacement}

The figure 5 shows variation of CMOD with temperature. In fact, figure 5 shows a family of curve where load is the parameter. The value of CMOD increases as the temperature of the specimen increases. Also, as the load increases, the value of CMOD increases. This increase in the value of CMOD with the increase in temperature can be attributed to the fact that as the test temperature increases, a drop in the mechanical properties can be noticed.

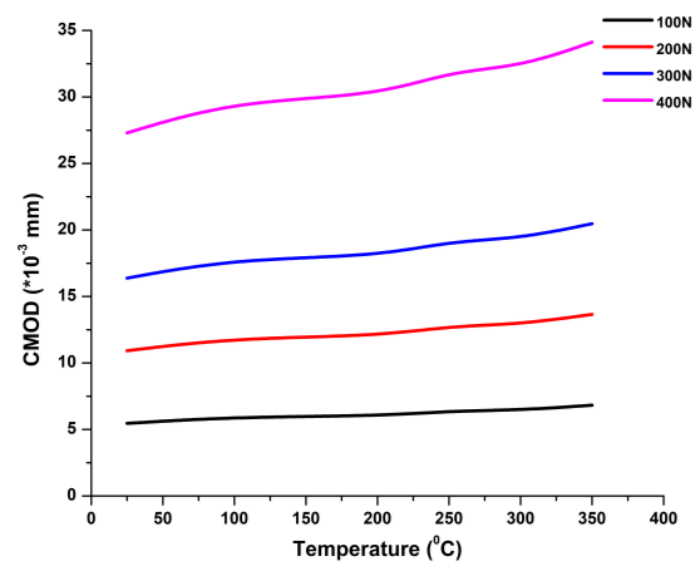

Figure 5. Variation of CMOD with temperature at different load

This drop in mechanical property results in the softness of the test piece, which results in the increase of the CMOD value at a constant load. It can be seen from the plot that the change in CMOD value with the change in temperature is less at $100 \mathrm{~N}$, however, at $500 \mathrm{~N}$ this change is considerably high. Hence, it can be deduced that the CMOD with an increase in temperature but this increase is noticed less at low load while the change is high at higher loads.

\subsection{Effect of temperature on crack mouth opening displacement}

The variation of CTOD with respect to temperature at varying loads can be seen in figure 6 where temperature is kept on the $\mathrm{X}$-axis and the CMOD on the Y-axis. The plot clearly indicates that as the temperature increases, the ultimate tensile strength decreases which makes the material soft and the crack propagation becomes easy. The value of CTOD for a particular load increases as the temperature of the specimen increases, and as the temperature reaches the higher side, the change in CTOD value also increases.

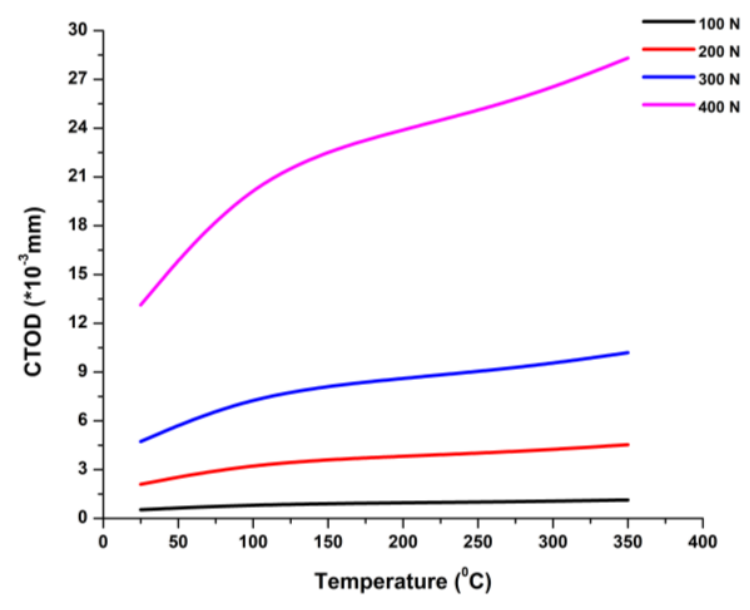

Figure 6. Variation of CTOD with temperature at different loads

\subsection{Effect of temperature on stress intensity factor}

Figure 6 represents the plot of stress intensity factor with respect to the temperature of the specimen. It can be seen from the plot that as the temperature increases for a particular load, the value of stress intensity factor attains an almost constant value and no change or very little change can be seen in SIF with the change in temperature.

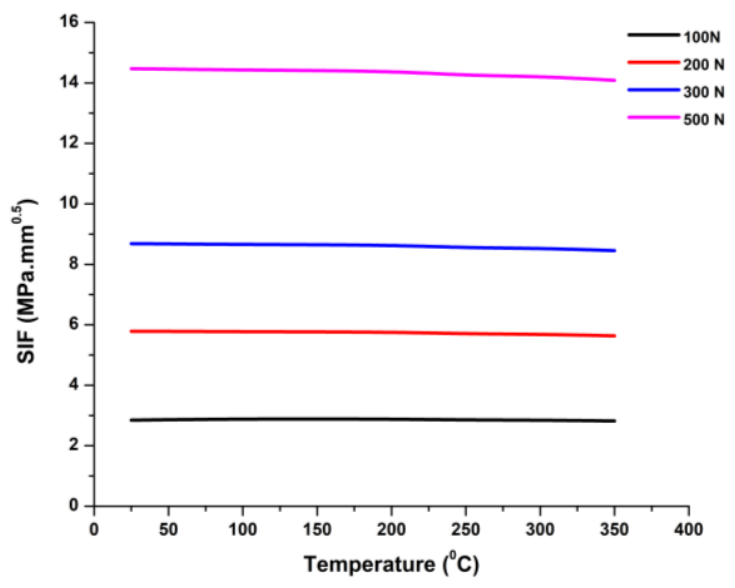

Figure 7. Variation of SIF with respect to temperature

However, with the increase in load, the SIF can be seen to increase. It can be said from the graph that the stress intensity factor is almost independent of the temperature and only depends on the size of the specimen and the load applied.

\section{CONCLUSION}

The numerical study to know the effect of temperature on the fracture parameters has been carried out successfully for different loads. The following conclusions can be drawn from the study:

1. The CMOD increases with the increase in temperature for a constant load. The change is small at light loads whereas, the change is considerably more at high loads.

2. The value of CTOD increases with the increase in temperature of the specimen for a constant load. 
3. The stress intensity factor is independent from the change in temperature at a constant load, while with the increase in load the SIF also increases.

The present study can be incorporated with the experimental study and at even higher temperatures where the phase change of the material starts and can be implemented on many other materials that are used extensively these days.

\section{REFERENCES}

[1] Broek, D. (2012). Elementary engineering fracture mechanics. Springer, Germany.

[2] Wells, A.A. (1961). Unstable crack propagation in metals, cleavage and fast fracture. Proceedings of the Crack Propagation Symposium, 210-230.

[3] Wells, A.A. (1963). Application of fracture mechanics at and beyond general yielding. British Welding Research Association Report.

[4] Singh, A., Kumar, S., Yadav, H.L. (2018). Numerical Parametric study of crack parameters near crack tip. International Journal of Mechanical and Production Engineering Research and Development (IJMPERD), 8(1): 83-92. https://doi.org/10.24247/ijmperdfeb20189

[5] Singh, A., Kumar, S., Yadav, H.L. (2018). Modelling, Measurement and Control B. 87(2): 101-106. https://doi.org/https://doi.org/10.18280/mmc_b.870207

[6] Rincon, E., Lopez, H.F., Cisneros, M.M., Mancha, H. (2009). Temperature effects on the tensile properties of cast and heat-treated aluminum alloy A319. Materials Science and Engineering, 519(1-2): 128-140. https://doi.org/10.1016/j.msea.2009.05.022

[7] Shojaei, K., Sajadifar, S.V., Yapici, G.G. (2016). On the mechanical behavior of cold deformed aluminum 7075 alloy at elevated temperatures. Materials Science and Engineering, 670: 81-89. http://dx.doi.org/10.1016/j.msea.2016.05.113

[8] Li, L.T., Lin, Y.C., Zhou, H.M., Jiang, Y.Q. (2013). Modeling the high-temperature creep behaviors of 7075 and 2124 aluminum alloys by continuum damage mechanics model. Computational Materials Science, 73:
72-78. https://doi.org/10.1016/j.commatsci.2013.02.022

[9] Standard, A. (2009). Standard test methods for elevated temperature tension tests of metallic materials. ASTM International, E21-09.

[10] European Committee for Standardization (CEN). (2007). Eurocode 9: Design of aluminum structures-Part 1-2: Structural fire design. BS EN 1999-1-2:2007, Brussels.

[11] Hadianfard, M.J., Healy, J., Mai, Y.W. (1994). Temperature effect on fracture behaviour of an alumina particulate-reinforced 6061-aluminum composite. Applied Composite Materials, 1(2): 93-113. https://doi.org/10.1007/BF00567572

[12] Derpenski, Ł., Seweryn, A. (2019). Ductile fracture of Notched aluminum alloy specimens under ELEVATED temperature part 2-numerical modelling and fracture criterion. Theoretical and Applied Fracture Mechanics, 102: 83-97. https://doi.org/10.1016/j.tafmec.2019.01.023

[13] Derpenski, Ł., Seweryn, A. (2019). Ductile fracture of Notched aluminum alloy specimens under ELEVATED temperature part 1-numerical modelling and fracture criterion. Theoretical and Applied Fracture Mechanics, 102: $70-82$. https://doi.org/10.1016/j.tafmec.2019.04.001

[14] Su, M.N., Young, B. (2017). 10.37: Mechanical properties of high strength aluminum alloy at elevated temperatures. ce/papers, 1(2-3): 2831-2839. https://doi.org/10.1002/cepa.334

\section{NOMENCLATURE}

CMOD Crack Mouth Opening Displacement

CTOD Crack Tip Opening Displacement

SIF Stress Intensity Fcator

LEFM Linear Elastic Fracture Mechanics

W Width of the specimen

S Span length

a Crack length

B Thickness of the specimen 